\title{
Urogenital tract infections in pregnancy at King Edward VIII Hospital, Durban, South Africa
}

\author{
M Dietrich, A A Hoosen, J Moodley, S Moodley
}

\begin{abstract}
Objectives-To evaluate the role of detecting asymptomatic bacteriuria and endocervical infections in the black prenatal patients attending King Edward VIII Hospital (KEH), Durban, with the view of justifying a screening programme. Screening for syphilis and human immunodeficiency virus (HIV) infection were also evaluated.
\end{abstract}

Subjects-181 asymptomatic black prenatal patients attending the antenatal clinic for their first antenatal visit volunteered for the study and gave their written consent.

Design-Examination of each prenatal patient included obtaining of endocervical swabs to detect endocervical infections ( $C$ trachomatis, $N$ gonorrhoeae), serum for syphilitic and HIV testing, and a midstream specimen of urine for microscopy and culture.

Results-Asymptomatic bacteriuria was found in $5.6 \%$ of patients in this study. Cervical infections were diagnosed microbiologically in $8.2 \%$ of women. These were $N$ gonorrhoeae in $4 \cdot 1 \%$ and $C$ trachomatis in $4 \cdot 7 \%$. Serological tests for sexually transmitted diseases showed the presence of syphilis in $7.6 \%$ and antibody to the HIV in $1.9 \%$. Overall, one or more sexually transmitted diseases were found in $16.5 \%$ of the women studied.

Conclusions-This study suggests that all women presenting for routine antenatal care in a setting such as Durban should be screened for lower genital tract infections. Ideally this should include a midstream urine specimen for culture, serum for syphilitic and HIV antibody testing and endocervical swabs for sexually transmitted pathogens. In developing communities, however, more reliable and cheaper methods of endocervical screening need to be available before antenatal screening for cervicovaginal infections can be justified.

Obstetric Researc Group, Faculty of Medicine, University of Natal, PO Box 17039, Congella, 4013, South Africa

M Dietrich

A A Hoosen

J Moodley

$S$ Moodley

Address correspondence to: Dr J Moodley

Accepted for publication 22 October 1991 plications. In pregnancy, sexually transmi pathogens, in particular organisms causing cervico-vaginal infections, have additional significance because they may lead to premature rupture of membranes, preterm labour and intra-uterine death. ${ }^{1}$ These complications are thought to be consequent upon transplacental spread or chorioamnionitis due to ascending infection. Foetal acquisition may also occur at the time of delivery. Hillier et $a l^{1}$ isolated micro-organisms more commonly from pregnant women with chorioamniomitis than those without. Complications of infections with Neisseria gonorrhoeae and Chlamydia trachomatis in pregnancy include post-partum endometritis, ${ }^{2}$ ophthalmia neonatorum ${ }^{3}$ and neonatal pneumonitis. ${ }^{4}$

Bacterial infections of the urinary tract, most of which are asymptomatic, represent one of the common medical complications of pregnancy. Of greatest concern is the risk of developing pyelonephritis and its complications including septicaemia and preterm delivery. ${ }^{5}$

Data on lower urogenital tract infections in pregnancy in developing communities are lacking. Currently, there is no screening programme for asymptomatic bacteriuria or lower genital tract infections caused by $N$ gonorrhoeae and $C$ trachomatis in pregnancy at King Edward VIII Hospital (KEH), Durban. However, a screening programme for syphilis is well established and screening for antibody to the human immunodeficiency virus (HIV) in pregnant women has recently been introduced. This study was therefore performed to determine the prevalence of asymptomatic bacteriuria and sexually transmitted pathogens in women attending the antenatal clinic with the view of justifying the need for a screening programme.

\section{Methods}

Subjects

The study group comprised 181 black pregnant women attending the antenatal clinic of $\mathrm{KEH}$ for their first antenatal visit (booked visit). $\mathrm{KEH}$ is a large urban referral hospital for the Province of Natal serving an underprivileged population. Rates of cervicovaginal infections in this population have been found to be high. ${ }^{6} N$ gonorrhoeae, $C$ trachomatis, $C$ albicans, $T$ vaginalis and syphilis were detected in $5.4,11.4,26.9,49.2$ and $11.9 \%$ of pregnant women respectively. ${ }^{6}$ Informed consent was obtained from all subjects. All were asymptomatic and denied having taken antibiotics or having used vaginal douches/pessaries in the 2 weeks prior to their visit. The age, parity and gestational period of each patient were recorded and all were examined by one of the authors (MD). 


\section{Microbiology}

Following routine general and obstetric examination, a speculum was passed to visualise the vagina and cervix. The cervical os was cleaned with cotton wool. Thereafter, two sterile cotton tipped swabs were introduced consecutively $1-2 \mathrm{~cm}$ into the endocervical canal and an attempt made to detect mucopurulent cervicitis (MPC) by looking at the colour of the second swab. A yellow colour indicated the presence of mucopus. Induced endocervical bleeding was also recorded. Thereafter, one endocervical swab was placed in Stuart transport medium and sent to the laboratory for culture on modified New York City medium (MNYC) for the isolation of $N$ gonorrhoeae. The second swab was used to prepare a smear for direct immunofluorescence staining (Microtrak, Syva, USA) to detect $C$ trachomatis antigen.

Each patient was asked to submit a midstream specimen of urine (MSU). These specimens were transported to the laboratory on ice for microscopy and culture on cystine lactose electrolyte deficient (CLED) medium. All bacterial isolates were identified using conventional laboratory methods. The MSU specimens were also tested for the presence of any antimicrobial substances. Of these, 11 $(6 \cdot 1 \%)$ tested positive, and were therefore excluded from further analysis.

Venous blood samples were collected from each subject for serological tests for syphilis and antibody to the human immunodeficiency virus (HIV) The Rapid Plasma Reagin (RPR) test (Becton Dickinson) was used to screen for syphilis. All reactive sera were titred and subjected to confirmatory tests-the Treponema pallidum haemagglutination (TPHA) (Fujirebio) or the Fluorescent

Table 1 Patient characteristics $(n=170)$ *

\begin{tabular}{lcc}
\hline & Mean & Range \\
\hline Age (years) & $26 \cdot 1$ & $15-45$ \\
Parity & $1 \cdot 7$ & $0-8$ \\
Gestational age in weeks & 30.5 & $14-42$ \\
\hline
\end{tabular}

*Of the 181 women, 11 were excluded because of antimicrobia substances in the urine.

Table 2 Sexually transmitted pathogens

\begin{tabular}{llcl}
\hline & & Number positive (\%) & Number tested \\
\hline Endocervical & N. gonorrhoeae & $7(4 \cdot 1)$ & 170 \\
Specimens & C. trachomatis & $8(4 \cdot 7)$ & 170 \\
Serology & Syphilis & $13(7 \cdot 6)$ & 170 \\
& HIV-antibody & $2(1 \cdot 9)$ & $107^{\star}$ \\
\hline
\end{tabular}

*HIV-antibody testing was only introduced midway through study.

Table 3 Results of mid-stream urine specimens $(n=160)$ *

\begin{tabular}{llc}
\hline Count $/ \mathrm{ml}$ & Micro-organism & Number positive (\%) \\
\hline & Klebsiella pneumoniae & $5(3 \cdot 1)$ \\
& Escherichia coli & $3(1 \cdot 9)$ \\
& Enterobacter agglomerans & $1(0 \cdot 6)$ \\
$10^{4}-10^{5} \mathrm{CFU} / \mathrm{ml}$ & Streptococcus agalactiae & $1(0 \cdot 6)$ \\
& E. coli & $5(3 \cdot 1)$ \\
Total of $>10^{5} \mathrm{CFU} / \mathrm{ml}$ & Staphyloccus saprophyticus & $1(0 \cdot 6)$ \\
Total of $10^{4}-10^{5} \mathrm{CFU} / \mathrm{ml}$ & & $9(5 \cdot 6)$ \\
Total of both counts & & $7(4 \cdot 4)$ \\
\hline
\end{tabular}

* 10 specimens not available for analysis due to leakage of specimens/breakage of containers in transit.
Treponema Antibody Absorbent (FTA-Abs) (Wellcome Diagnostics) tests. HIV antibody testing was performed using a recombinant HIV-1/HIV-2 Elisa kit (Abbott Diagnostics) and sera confirmed by Western Blot (Diagnostic Biotechnology).

\section{Results}

The patient characteristics are shown in table 1 . One hundred and thirty-one $(77 \cdot 1 \%)$ patients were in the third trimester and none in the first trimester of pregnancy. Fifty-six $(32.9 \%)$ patients were nulliparous and 24 $(14 \cdot 1 \%)$ were less than 20 years of age.

The prevalence of sexually transmitted pathogens is shown in table 2 . Twenty eight $(16.5 \%)$ patients were infected with one or more sexually transmitted diseases. Only two patients had mixed infections, one having $N$ gonorrhoeae with $C$ trachomatis and the other syphilis with $C$ trachomatis. One gonococcal isolate was penicillinase producing (PPNG).

The clinical swab test indicated the presence of mucopus in only one of 14 cases $(7 \cdot 1 \%)$ of cervical infections. However, induced endocervical bleeding was observed in 78 $(60.9 \%)$ of the 128 women evaluated.

The bacteriological results of the urine specimens are shown in table 3 . Sterile pyuria (that is greater than 10 leukocytes per high power field $\times 400$ ) was found in 27 of 160 urine specimens. However, in 24 of these, squamous epithelial cells were also seen on microscopy suggesting vaginal contamination. Significant bacteriuria in association with STD was found in two patients; one with syphilis and the other with a gonococcal infection.

\section{Discussion}

The prevalence of asymptomatic bacteriuria during pregnancy ranges from $4 \%$ to $11.8 \% .^{78}$ However, data from studies on screening are not always comparable owing to different definitions of bacteriuria. ${ }^{9}$ Since the classic studies of Kass, ${ }^{10-12}$ a culture of midstream urine containing $\geq 10^{5} /$ colony forming units (CFU)/ml has been accepted to represent significant bacteriuria. It should be noted that this criterion was established in asymptomatic women. More recently, Stamm ${ }^{13}$ suggested that lower counts $\left(\geq 10^{2} \mathrm{CFU} / \mathrm{ml}\right.$ ) be used to diagnose significant bacteriuria in symptomatic women

In this study, the prevalence of significant bacteriuria $\left(\geq 10^{5} / \mathrm{CFU} / \mathrm{ml}\right)$ was $5 \cdot 6 \%$. Twenty-four of 27 urine specimens demonstrating sterile pyuria were excluded from analysis because of the evidence of squamous epithelial cells suggesting vaginal contamination. The true prevalence rate of asymptomatic bacteriuria may therefore be higher, especially if the three cases of sterile pyuria without evidence of vaginal contamination be included.

Although the dipstick method of screening has been suggested as a rapid method to detect asymptomatic bacteriuria, unpublished data from the Microbiology Laboratory at King Edward VIII Hospital indicate a poor correlation between the dipstick method and culture 
techniques. Furthermore, the changing pattern of bacterial resistance to antimicrobial agents makes the dipstick method of screening of limited value. We therefore recommend routine screening of bacteriuria by conventional methods.

Of the women studied $16.5 \%$ ( 28 of 170 ) had evidence of a sexually transmitted infection (table 2). Cervical infections were diagnosed microbiologically in $8.2 \%$ (14) of these women. Previous reports ${ }^{14}$ have suggested that induced endocervical bleeding and the presence of mucopus may be considered as clinical evidence of the presence of $C$. trachomatis and/or $N$. gonorrhoeae. In this study $C$ trachomatis and $N$. gonorrhoea were detected in $4.7 \%$ and $4.1 \%$ of patients respectively. However, clinical evidence of cervicitis was difficult to evaluate because of the high percentage $(60.9 \%)$ of women with induced endocervical bleeding. Although we are uncertain of the exact cause of the endocervical bleeding, previous reports from our hospital show high prevalence rates of vaginal infections, ${ }^{16}{ }^{17}$ suggesting a possible mechanism in induced bleeding.

It is well established that HIV infection is transmitted predominantly by heterosexual means in Africa. Moreover, it is much commoner in young sexually active women (aged 15-25 years). ${ }^{18}$ These features bear particular relevance to obstetric, midwifery and neonatal paediatric practice. It is estimated that $30-50 \%$ of babies born to HIV antibody positive mothers will be infected by the virus and the majority will become symptomatic in early life. Infection may be acquired in utero, at birth or possibly post-natally through breast feeding. Therefore, the finding of $1.9 \%$ antibody positivity suggests that routine screening for HIV antibodies should be instituted at all ante-natal clinics.

Recently a few reports ${ }^{19}$ emanating from developed communities have questioned the cost-effectiveness of screening for syphilis in antenatal patients. Our finding of $7 \cdot 6 \%$ reactive syphilis serology is in keeping with previous reports from $\mathrm{KEH}^{2021}$ and argues strongly for ongoing screening in our community.

In conclusion, this study advocates that all women presenting for routine ante-natal care should have a midstream urine taken for culture and serum for HIV antibody testing, in addition to serological screening for syphilis. Until cheaper and reliable methods of endocervical screening are available, routine screening for endocervical infections is not feasible at our hospital.

1 Hillier SL, Martins J, Krohn M, Kiviat N, Holmes KK, Essenbach DA. Case control study of chorio-amniotic infection and chorio-amnionitis in prematurity. $N$ Engl $J$ Med 1988;319:972-8.

2 Wager GP, Martin DH, Kontsky L et al. Puerperal infectious morbidity: relationship to route of delivery and to antepartum Chlamydia trachomatis infection. Am J Obstet Gynecol 1980;138:1028-33.

3 Fransen L, Nsanze H, Klauss V et al. Ophthalmia neonatorum in Nairobi, Kenya: the roles of Neisseria gonorrhoeae and Chlamydia trachomatis. J Infect Dis 1986;153:862-69.

4 Schaefer C, Harrison HR, Boyce WT, Lewis M. Illnesses in infants born to women with Chlamydia trachomatis infection. Am J Dis Child 1985;139:127-33.

5 McNeeley SG. Treatment of urinary tract infections during pregnancy. Clin Obstet Gynecol 1988;31:480-7.

6 O'Farrell N, Hoosen AA, Kharsany ABM, van den Ende J. Sexually transmitted pathogens in pregnant women in a rural South African community. Genitourin Med 1989, 65:276-80.

7 Norden CW, Kass EH. Bacteriuria of pregnancy: a critical appraisal. Ann Rev Med 1968;19:431-70.

$8 \mathrm{Chng}$ PK, Hall MH. Antenatal prediction of urinary tract infection in pregnancy. Br J Obstet Gynaecol 1982;89: 8-11.

9 Dairiki Shorliffe LM. Asymptomatic bacteriuria: should it be treated? Urology 1986;27(Suppl 2):19-25.

10 Kass EH. Chemotherapeutic and antibiotic drugs in the management of infections of the urinary tract. Am J Med 1955;18:764-81.

11 Kass EH, Finland M. Asymptomatic infections of the urinary tract. Trans Assoc Am Physicians 1956;69:56-64.

$12 \mathrm{Kass} \mathrm{EH}$. Bacteriuria and the diagnosis of infections of the urinary tract, with observations on the use of methionine urinary tract, with observations on the use of methionine

13 Stamm WE, Counts GW, Running KR, Fihn S, Turck M Holmes KK. Diagnosis of coliform infection in acutely dysuric women. N Engl J Med 1982;307:463-68.

14 Braddick MR, Ndinya-Achola JO, Mirza NB, et al. Towards developing a diagnostic algorithm for Chlamydia trachomatis and Neisseria gonnorrhoeae cervicitis in pregnancy. Genitourin Med 1990;66:62-65.

15 Brunham RC, Paavonen J, Stevens CE, et al. Mucopurulent cervicitis- the ignored counterpart in women of urethritis in men. N Engl J Med 1984;311:1-6.

16 Hoosen AA, Ross SM, Mulla MJ, Patel M. The incidence of selected vaginal infections among pregnant urban Blacks. selected vaginal infections among

17 Hoosen AA, Kharsany ABM, Moodley J, van den Ende J. The prevalence of selected vaginal infections in pregnancy: a comparative study in three racial groups. Pape presented at the Infectious Diseases and Sexually Transmitted Diseases Congress, Durban 14-16 October 1987 Abstract 038.

18 O'Farrell N, Windsor I, Becker P. HIV-1 infection among heterosexual attenders at a sexually transmitted disease clinic in Durban. $S$ Afr Med J 1991;80:17-20.

19 Clay JC. Antenatal screening for syphilis. BMJ 1989, 299:409-10.

20 Manning B, Moodley J, Ross SM. Syphilis in pregnant black women. S Afr Med J 1985;67:966-7.

21 Naicker S, Moodley J. Serological diagnosis of syphilis in pregnancy. S Afr Med J 1983;63:536-7. 